\title{
The Analysis of Music Elements in Li Bai's Poems
}

\author{
Xiaona Zhao ${ }^{1}$, Yanshuang Hou ${ }^{2,3,4}$, Xinglong Guo ${ }^{4, *}$ \\ ${ }^{1}$ School of Music, Mianyang Normal University, Mianyang City, China \\ ${ }^{2}$ School of Education, Tianjin University, Tianjin City, China \\ ${ }^{3}$ School of Music, University of Jinan, Jinan City, China \\ ${ }^{4}$ The Institute on Libai of Sichuan Province, Libai Research Center, Mianyang City, China \\ *Corresponding Author
}

Keywords: Li Bai's poems, Music elements, Music thoughts.

\begin{abstract}
From the present research results, most studies on Li Bai's poems are from the angle of literary poetry, and few people pay attention to the music elements and music ideas in his poems. This paper starts from the background of politics, economics, culture and history in Tang Dynasty, focuses on Li Bai's culture belief foundation and his poetry works on music-accompanied dance, attempts to explore the causes, performance and the nature of the music thoughts in Li Bai's poems by combining previous research results. In this way, the author hopes to learn more about music thoughts from Tang Dynasty, enrich the understanding of poets, and broaden the new field of Li Bai's poetry research.
\end{abstract}

\section{Introduction}

Li Bai (701-762), whose courtesy name was Taibai, and was also known as the Hermit of Green Lotus. He is a great romantic poet of Tang Dynasty. Li Bai worships La Tzu and Chuang Tzu, and learns Taoism all his life. In the ancient times, poetry and music were as one thing. Poetry was the core and music was the carrier. This reflects the creation character of poetry and music at that time. In early Tang Dynasty, Cui Rong is the representative in theory. Li Bai is one of the poets who struggles much toward this direction in the glorious age. Li Bai is fond of Yuefu poems in Wei and Han dynasties. According to incomplete statistics from the Collection of Yuefu Poems written by Maoqian Guo. Li bai's poems account for about a third of the total Yuefu poems in Tang Dynasty. In his Yuefu poems, the poems of Wei and Han dynasties (such as Sauvignon Blanc and Hard Roads in Shu) occupies a large proportion, reaching over 80 percent. The remaining are new Yulefu and there are also 11 modern poems. In his works, music is always with poems, which makes poems be like lyrics; or poems are used to describe music, which makes these poems a sense of aesthetics and a character of music art; Or rhythm of the inner life and emotion are transformed into the rhythm of poems, which makes poems have a unique artistic charm. All in all, Li Bai has put music in his works, and his poems embody the artistic characteristics of the integration of poetry and music.

In the Study on Li Bai's Poetry and Music : Problems and Breakthrough Path, "In Tang Dynasty, poetry and music influenced with each other, restricted with each other, and promoted with each other. The creation of poems is either according to music or in reverse. Poets and musicians were together with each other, co-prosperity and symbiosis."

From the music characteristics of the poetry, the Verses in Qing Ping Tune written by Li Bai is the master work. According to Song Chiang (pine window) Melange by Jiao Wei in Tang Dynasty, when Li Bai was required by the emperor to create Verses in Qing Ping Tune, "he hasn't been awake from the alcohol." "Li Bai then created the poems. Li Guinian soon made the melody to match up with the poems. The emperor then asked the instrumentalists to play some music according to the melody, which meant to force Li Guinian to sing. Concubine Taizhen held the glass cup with seven jewels and put the grape wine in it, comprehend its meaning with smiles. Thus the emperor himself played flute for the poems. Every time he finished a song and change another, he lengthened the flute's melody to 
make Taizhen happy." From this, we can see that Li Bai knows deeply about the music characteristics of this kind of works. At that time, Li Bai has created lyrics Pu Sa Man, Yi Qin E, Qing Ping Le, Lian Li Zhi and Gui Dian Qiu. Wang Wei, Li Bai and Wang Changling are the talents of five words quatrains and seven words quatrains in glorious age of Tang Dynasty. The evaluation of "excellence" is not only for their poems, but also for the music characteristics in their works. Li Bai's lyrics represent people's aesthetic pursuit of poetry in Tang Dynasty, which is to meet the need of music. It forms a unique unit of music. That is to say, its performance is particularly strong, which is easy to express, easy to write and narrative, and easy to translate into lyrics that can be sung. Thus, the quatrains became the most prominent object for the poets in Tang Dynasty to add music into it. Not only five words quatrains and seven words quatrains, Yuefu poems can also be sung. By contrast, in Li Bai's poems, the Yuefu poems such as Zi Ye Ge, Yang Pan Er, Wu Ye Ti can still be sung at that time. "The writing methods vary a lot and keep changing, the emotion is like fast and powerful thunder, chill wind and heavy rain, which is a song. The arrangement is strict, the context is connected, the content is fluent, that is like a road. Li Bai's poems are more like a song, Du Fu's poems are more like a road". From this description, it is easy to see the characteristics of Li Bai's Yuefu poems and song-form poems, although we don't know how to sing them.

\section{The Works of Music in Li Bai's Poems}

There is commonality between music and poetry, and also similarities of images and artistic conception between poetry and music. Many of Li Bai's poems which describe music, reflect the thought of Chinese music aesthetic perception and music artistic peculiarity. They also show the Chinese music appreciation and awareness of the poetic conception, situation and picturesque scene. There are a lot of poems of Li Bai which describe music. Such as the second one of In Imitation of Old Poems, A Trip in Spring, Phoenix who plays the Sheng, Watching a Barbarian Play Flute, Farewell to Wu Zhang at Midnight, and A Silent Spring. Among these, Listening to a Monk of Shu Who Plays Chinese Zither is the most typical one: This monk with his zither comes from the land of Shu. He goes down the high Mount Emei from the west. Plucking the strings, he played for me. I heard murmuring pines in many valleys. Like flowing water, the music cleansed my heart. Leaving its echo in the frosty bell. Dusk came unnoticed to these green hills. As the autumn clouds grew darker and darker. There is another one called Listening to Zishun Lu Playing Chinese Zither: Sitting under the moonlight when I am free, listening to Mr. Lu playing zither. I hear the melody of Sad Wind, but it also seems like the tune of Pine Trees in Winter. The fingering in White Snow makes you busy, the melody of Green Water makes me calm. Ziqi Zhong has been disappeared for a long time, there is no more soul mates like him. These works make music imagery and with artistic conception. The "poetic meaning with picturesque scene" coincides with music's "poetic sentiment". He felt grandness which is like pine trees in valleys. He felt a sense of silence "Like flowing water, the music cleansed my heart. Leaving its echo in the frosty bell". He felt a sense of heaviness when "Dusk came unnoticed to these green hills. As the autumn clouds grew darker and darker." When he listened to the zither played by Lu, he not only felt the sad tone, the silence of the melody in Green Water, but also sighed deeply for the difficulty in finding a soul mate. In these poems, the emotion flows and the images comes one after another. Poetry and music make the nature integrate with human's "ambition", "knowledge", "talents", "human nature" and "emotion". For Li Bai, the zither melody made by the monk from Shu or Lu is mixed by their inner feeling and experience of nature, life and society, so that it sounds beautiful. Li Bai transforms it into the artistic conception of poetry, which is the connection between the poetry and music.

\section{The Tune and Rhythm in Li Bai's Poems}

Because of the similarities between the aesthetic feeling of poems and music, it becomes natural to use the feeling of music to evaluate poems. For example, in The Anthology of Poems in Tang Dynasty written by Deqian Shen, he comments Li Bai's poem Walking to Shang Liu Tian as:” The last line of the poem has so many different tones and rapid rhythm, it is just like a piece of music." 
Music is the art of rhythm and melody, and so is poetry. On the one hand, it shows that Li Bai's poems have the beauty of music. On the other hand, the ancient poetics emphasized the poet's music quality. It is obvious that Li Bai, in the preparation of Yuefu poems, noticed the melody styles, the rhythm and other primitive characteristics. Li Bai uses his spirit to see the space and everything, which is just the space consciousness shown in Chinese poetry and paintings. In The Anthology of Illustrious Poets of the Country collected by Bo Yin, "Speaking of Difficult Roads in Shu and some other poems of Li Bai, it is quite surprising. It is hard to find this kind of illustrious poems." It belongs to "Xiang He Ge" in Collection of Yuefu Poems. In Han Dynasty, "Xiang He Ge" is a kind of old songs accompanied by music. However, in Tang Dynasty, its melody had been disappeared for a long time, only its literature value left. Li Bai's poem Difficult Roads in Shu still shows obviously its melody and rhythm. From the view of the sentence pattern, the whole poem is dominated by seven words, and there are also short sentences with only three words and long sentences with eleven words, which constitute a rhythm of ups and downs. Especially the sentence "roads in Shu is difficult, just like climbing up to heaven" is repeated three times in the poem, which gives readers a feeling of a sigh. In The Anthology of Poems in Tang Dynasty written by Deqian Shen, he leaves the following comment for the poem Difficult Roads in Shu: "the momentum in the poem is sometimes like a dragon flying, sometimes like an insect crawling. It is just like a thunder starts from your fingers." Li Bai uses the inner emotional rhythm to unify the external sentences and the emotional appeal of the tune. He mixes these two aspects harmoniously. The structure and function interact as both causes and effects. We can feel the power of this poem from its melody. Another example is the comments on the poem A Song of Xiang Yang in the book Zhao Mei Zhan Yan written by Dongshu Fang. It says that it is a poem to express the anger and complaint. "We own the wind and the moon without paying; I am drunk and fall down without been pushed. Let's hold the wine cups. I will live or die with you." These sentences comes from Li Bai's drunk situation and his abundant emotion. He puts seriousness into humor, and sadness into happiness. The rhythm of the poem and the poet's emotion constitute a complete organism. His anger and complaint are revealed in the rhythm of the natural change of the poem. It would be nice to attribute the free and relax style of the rhythm and melody in Li Bai's poetry according to the need of life and emotion to his talent skills. However, his aesthetic basis lies in the harmonious unity between the complicated thoughts and emotion and the rhythm and melody of his poems, which is the aesthetic feeling of music in Li Bai's poems.

\section{The Deep Understanding toward Musical Instruments in Li Bai's Poems}

$\mathrm{Li} \mathrm{Bai} \mathrm{is} \mathrm{fond} \mathrm{of} \mathrm{Chinese} \mathrm{zithers.} \mathrm{In} \mathrm{his} \mathrm{poetry,} \mathrm{once} \mathrm{there} \mathrm{is} \mathrm{a} \mathrm{scene} \mathrm{of} \mathrm{music,} \mathrm{and} \mathrm{there} \mathrm{will} \mathrm{be}$ Chinese zithers. Such as "How would I know if there was an immortal who was playing Chinese zither in heaven.", "Why am I alone when I am at my seventieth. This kind of sadness can't be fully expressed by Chinese zithers." Li Bai is fond of Chinese zithers and he is also good at playing it. The poem A Silent Spring describes the scene of him playing Chinese zither in the forest. He is also confident about it. He called himself "a man who will not be worse as the ancient talent musicians after drinking". In his poem An Ode to Chinese Zither, "There is a tung tree on the south of Mount Yi. Its trunk stretch to the sky. Its root grows near the cold spring. Its leaves are like the moon. People cut it to make a Chinese zither, which owns a fantastic sound. The sound brings people to a fantastic realm where wind in autumn blows, making the pines shaking." This involves the aesthetic view of the performing art of Chinese zithers, that is, its "fantastic" realm. The sound of the Chinese zither can attract people into the fantastic realm. At that time, the objects described by Chinese zithers are beyond earthly meanings. Pines are not pines any more, wind is also not wind any more. This is so called "fantastic". In another poem, he wrote: "holding the plectrum with the white jade, I start playing the Chinese zither. The spring in the silent valley is deep, which makes me worry and sad. I tighten the strings with my hands to make the tone high and bright......” The melody is like the water in the deep valley. It is also like the pines' shaking sound on the top of the mountain with monkeys' cry, which makes people weep sadly. The poet himself fully entered the realm of art. He only felt that the emotion of the moment was expressed by the Chinese zither, and he forgot whether the music he played was ancient or new. This kind of profound understanding of the artistic state of the Chinese 
zither "can't be told if you are not a master of it". In addition to the Chinese zither, Li Bai also has a large number of works to describe various musical Instruments, such as flute, se (a twenty-five-stringed plucked instrument, somewhat similar to the zither) and zithers. Such as" When Hu people play flute, most of the melody comes from Qin area". It showed that the songs played by flute spread widely. "It is a morning of October when I am on Mountain Wu, there is flute melody down on Mountain Jing-Ting". "The flute song Falling Plum Blossom is played at Yellow Crane Tower, it seems that plum blossom are falling down in the whole Wuhan". "The weather is still cold, the soldiers can only feel the smell of spring in the flute song Picking Willow Leaves". During Han and Wei dynasties, the northern nomadic folk songs Falling Plum Blossom and Picking Willow Leaves were still popular in Tang Dynasty. It can be seen that $\mathrm{Li}$ Bai has a high degree of identification of musical instruments, as well as a number of pieces of music.

\section{The Reasons for the Distinctive Music Characteristics of Li Bai's Poems are Multifaceted}

The first is the aesthetic needs of poetry itself. In addition to image selection and artistic conception, it also needs to have rhythm, metre, tone and so on. Poetry, like music, must be short and long, sad and happy, hard and soft, to make a harmonious melody. Since the poem is to be merged with music, the number and the pronunciation of words in the poem will be the same as the pitch, sound, and the number of scale. And the length and the number of the sentence must be the same as the pattern and the number of beats.

The second is the flourishing music art in Tang dynasty influenced the area of poetry creation. Tang Dynasty is an open era, the frequent exchange of Chinese and foreign cultures, not only contributed to the rapid development of music in Tang Dynasty by the integration of various nationalities and foreign music culture, but also contributed to the integration of poetry and music. The emergence of many poet musicians and many works depicting music, represented by Li Bai, fully proves the conclusions above, and shows that there is not only paintings in poetry, but also music.

The third is the deep quality of music art of Li Bai. Take his poem A Silent Spring as an example. The poem describes himself playing Chinese zither. The sound of Li Bai's playing can cause the listener who is sad and lose his ambition to cry with tears covering all his face. It is easy to find that $\mathrm{Li}$ Bai has an extraordinary knowledge of music. Li Bai with his feelings for music art, puts much effort to the poetry creation, which makes the poem naturally has the music aesthetic characteristics.

\section{Conclusion}

One of Li Bai's contribution to music development is reflected in the inheritance and preservation of music in the Han and Wei dynasties. Li bai created a large number of ancient Yuefu poetry. The most important part of the Yuefu poetry is its music internal quality. Most of the tune names of ancient Yuefu poetry are from the traditional music of Han Wei and six dynasties. That most of his ancient Yuefu poetry can be accompanied obviously shows that he noticed the music characteristics of Yuefu melody such as its tune styles, rhythm and beats when he chose the words. The specification and potential requirements of the music tunes were considered. Thus no matter it is Invitation to Wine , Ode to Gallantry with many different tones and rapid rhythm, or A Battle in the South of the Town, Farewell with complex tones, or Life's Journey is Hard, Reciting at Night with slow rhythm and deep emotion, Li Bai's poems make the ancient music be inherited and preserved to some degree. Li Bai's creation improved the quality of folk music literature. Everywhere he heard a beautiful folk song, he would imitate it to write poems. Such as A Song of Xiang Yang, which was created because he was touched by the folk song there. The poem A Song of Jing Zhou, which was created when he was in Jing Zhou, is more like a folk song. As he reached Wu Yue area, he had excellent works like A Poem for Ladies in Yue area (five poems), The Businessman's Trip, A Girl on Huan Sha Stone (Huan Sha Stone: stones for people to stand when they wash things by the river). Li Bai, with his high literary level of poetry with folk song style, has improved the quality of folk music literature and injected fresh vitality and elements into the development of folk songs. 


\section{Acknowledgement}

Project Number: the Li Bai Culture Research Center (Key research base on humanities and social science of Sichuan Provincial Department of Education, No.LB16-01) for funding required to carry out this work.

\section{References}

[1] [Song Dynasty] Maoqian Guo. Yuefu poetry [M]. Beijing: Zhonghua Book Company, 1979.

[2] Qiyun Guo. A Discussion on the Characteristics of Li Bai’s Yuefu Poems [J]. Guangxi Social Sciences, 1996, (2): 104.

[3] Ming Tang. The Combination and Separation of Scholar's Works and Folk Creation [J]. Tangdu Journal, 2000, (1): 37 - 41.

[4] Elegant Chinese Zither Songs, collected by Wang. Beijing, Zhonghua Book Company, Study on Yan Music, Miscellany and Lyrics of Sui, Tang and Five Dynasties, the first version in July, 2007, Kunwu Wang, Beijing, Zhonghua Book Company, first version in November 1996 